\title{
ESTADO, MERCADO Y SOCIEDAD EN EL CHILE DE LOS NOVENTA: ¿LA HERENCIA DE UN "MODELO DE MODERNIZACIÓN" AUTORITARIO?
}

\author{
STATE, MARKET AND SOCIETY IN CHILE OF THE NINETEEN- \\ NINETIES: THE INHERITANCE OF AN AUTHORITARIAN \\ MODEL OF MODERNIZATION?
}

\section{MÁXIMO QUITRAL ROJAS ${ }^{1}$}

\section{RESUMEN}

El siguiente trabajo plantea tres hipótesis centrales. La primera de ellas es que las transformaciones económicas ejecutadas por la tecnocracia chilena no fueron sinónimo de modernización. La segunda hipótesis se refiere a la desarticulación societal acontecida bajo el régimen autoritario. La tercera hipótesis estriba en el hecho de la desarticulación y reemplazo de la matriz sociopolítica latinoamericana (MSPL), por una matriz mercado-céntrica.

Palabras clave: Estado, matriz, dictadura, sociedad, globalización y modelo.

\section{ABSTRACT}

This paper studies three main hypotheses. The first is that economic change implemented by Chilean technocrats was not synonymous of modernization. The second hypothesis concerns the societal disruption which occurred under authoritarian rule. The third hypothesis rests on the fact of the dismantling and replacement of the Latin American sociopolitical matrix (MSPL) for an array-centric market.

Keywords: State, matrix, dictatorship, society, globalization and model.

Recibido: 18.12.10. Aceptado: 06.09.11.

\footnotetext{
${ }^{1}$ Historiador, Doctorando en Ciencia Política, Universidad Nacional de San Martín, Argentina. Magíster en Estudios Internacionales, Universidad de Santiago de Chile (USACH). Investigador del Instituto de Estudios Internacionales (INTE) de la Universidad Arturo Prat. Santiago, Chile.E-mail: maximoquitral@gmail.com
} 
y la acentuación de las familias en condiciones de pobreza: cerca del $45 \%$ para los años ochenta. Si el análisis se hiciera en términos del crecimiento las cifras serían interesantes: 8,3\% en 1977; 7,8 en 1978; 7,1 en 1979 y 7,7 en 1980, llegando a considerar que el monetarismo ortodoxo era eficiente. Pero lo concreto es que estos datos fueron a costa del derrumbe del manejo del Estado, de la indiferencia hacia los sectores sociales más vulnerables y condicionando a Chile a ser un país erosionable a las perturbaciones cíclicas. En términos económicos el legado de la dictadura tuvo efectos a largo plazo, pero, en lo estrictamente social y en el rol del Estado, sus secuelas fueron inmediatas. Chile no sería el mismo económicamente y el Estado y la sociedad, desmembrados profundamente.

A partir de estos elementos, el siguiente trabajo plantea tres hipótesis centrales sobre el nuevo Chile que emerge postgolpe militar. La primera de ellas es que de ninguna manera las transformaciones económicas ejecutadas por la tecnocracia chilena fueron sinónimo de modernización plena, sino que más bien fueron parciales e identificadas con tres procesos. Uno, los cambios estructurales utilizados en ese entonces sólo favorecieron a un segmento reducido del sector privado en desmedro del resto de la población. Dos, se evidenció un alza en la concentración económica, producto de los privilegios adquiridos por los empresarios y el pleno control de las entidades financieras. Tercero, crecimiento económico y desarrollo social no estuvieron en congruencia, dejando altas cifras de desempleo y experimentando una ostensible baja en los salarios reales.

La segunda hipótesis se refiere a la desarticulación societal acontecida bajo el régimen autoritario, la que era viabilizada por la política y articulada por el Estado. El resultado de dicha fragmentación supone el paso de una sociedad industrial con fuerte presencia del Estado nacional a una nueva sociedad post-industrial y altamente globalizada. Al producirse ese forzoso debilitamiento del Estado y su involuntario reemplazo por las fuerzas del mercado, la relación entre el Estado y la sociedad se torna mucho más inconexa, provocando que la sociedad percibiera la política como algo carente de importancia suprema.

La tercera hipótesis estriba en el hecho de la desarticulación y reemplazo de la matriz sociopolítica latinoamericana (MSPL) por una matriz mercado-céntrica o neoliberal. La característica principal de la MSPL fue su fuerte vínculo entre el Estado, los partidos políticos y la sociedad. La expresión más fuerte de la canalización del movimiento colectivo fue la política, desarrollada ampliamente por la sociedad y encauzada en la militancia de los partidos. Sin embargo, los regímenes autoritarios destruye- 
ron dichas formas de comportamiento social, fragmentaron a la sociedad y provocaron la atomización de la sociedad. El Estado, al ser insolvente para el autoritarismo, permitió la ubicación del mercado en el centro de las decisiones, permitió la absoluta despolitización de la sociedad y fomentó la alteración de la relación entre economía y Estado. Finalmente la estructura del trabajo está compuesta por: i) una reflexión sociológica sobre Estado, mercado y sociedad, ii) las intenciones del régimen autoritario de Pinochet por romper con el Estado de compromiso y iii) un balance al proceso de transición democrática en el Chile de los noventa.

\section{ESTADO, MERCADO Y SOCIEDAD, UNA REFLEXIÓN DESDE LA SOCIOLOGÍA}

Como el proyecto militar chileno procuró desde su instalación revertir la implicancia política que desplegó el Estado por varias décadas y destruir sus mecanismos de vehiculización social, finalmente fue la tecnocracia nacional la que impulsó su debilitamiento y su posterior jibarización. Todos estos mecanismos provocaron una alteración de las relaciones entre el Estado y la sociedad y se fortaleció la imagen del mercado como fórmula de ascenso personal y social. Las acciones emprendidas desde el gobierno de facto robustecieron la tendencia inicial y remarcaron sus discrepancias con el Estado para el logro de sus objetivos. Aunque la teorización del Estado ha sido amplia, es recomendable generar una revisión de sus alcances para estructurar y profundizar algunas de sus trascendentales definiciones. Un primer axioma identifica al Estado como “(...) la institución fundamental de cada sociedad, la matriz de las demás instituciones, el principio coordinador o regulador con poder sobre toda la sociedad, y el aparato político que ejecuta ese poder" (Bresser-Pereira, 2009: 84). En esta explicación queda de manifiesto la importancia que tiene el Estado dentro de una sociedad, es la columna articuladora y movilizante de las aspiraciones de los individuos y es el organismo que ejecuta un poder sobre la sociedad. Sin embargo, este poder puede ser desplegado de manera represiva, aun cuando el Estado sea dirigido por una dictadura, pero de ninguna manera puede ser reconocido sólo con posiciones de dominación. Por ejemplo, para el politólogo Guillermo O’Donnell, el Estado sería

(...) una relación social de dominación o, con más precisión, un aspecto -como tal, sólo captable analíticamente- de las relaciones sociales de dominación (...) El Estado que aquí nos interesa es un tipo de estado 
capitalista. Como tal, respalda y organiza una dominación de clase, en el sentido de que es una dominación que tiene principal fundamento en una estructura de clases (...) En esta perspectiva el Estado es, primero y fundamentalmente, una relación de dominación que articula de manera desigual a la sociedad civil... (O’Donnell, 1997: 71).

Ese grado de parcelación que reconoce O’Donnell en el Estado se plantea desde un Estado que tiende a generar desigualdades por sobre la equidad social. Tal situación se produce bajo un Estado con dispositivos capitalistas, cuya intención es fraccionar a la sociedad en clases y a la reproducción de la totalidad de las relaciones capitalistas al interior de una sociedad determinada. Dicha tipificación pueda ser adaptable al Estado chileno de principios del siglo XX, pero para el período escogido para este trabajo no podría emplearse dicha calificación. Además, no es posible reconocer en el Estado un alto componente de dominación social, pues su razón de ser lo dirigiría a una posición totalitaria más que a una función de desarrollo social. Lo anterior daría justificaciones de sobra para provocar su destrucción total e impedir un crecimiento armonioso del Estado. Pese a todo, se puede argumentar que el Estado es un conjunto de variadas características y de múltiples dimensiones, ya sea simbólicas, instrumentales o meramente institucionales, pero que en ningún caso éstas pueden ser las fundamentales o que alguna de ellas sobrepase a la otra. El Estado, al ser parte integrante y relevante de la sociedad, está rodeado de elementos exógenos que lo sitúan en una dimensión mayor que la puramente instrumental y no como un organismo aislado. Éste tiene directa relación con la construcción histórica de los países, con el protagonismo de ciertos sectores sociales y con el grado de cohesión nacional que puede obtener. Esto quiere decir que "el Estado combina, por una parte, instituciones, instrumentos, actores y agentes simbólicos y concretos que gozan de relativa autonomía. Por otra parte, ejerce funciones coercitivas, reguladoras, redistributivas e integradoras según la esfera social con la que interactúa" (Garretón, 2004: 17). En resumen, el Estado asumiría una dimensión polifuncional, ya que representaría estrategias de desarrollo, mecanismos de dominación social, reflejaría funciones coercitivas, provocaría instancias de cohesión nacional y por cierto, fortalecería la institucionalidad necesaria para operacionalizar esas características. Su entendimiento por una parte y su procedimiento por otro están en directa relación con todos los elementos antes explicitados, pero determinados por cada nación y reforzados en ciertos momentos históricos.

Continuando con algunas concepciones del Estado, hay otras explicaciones teóricas que lo asocian con un desarrollo natural de los individuos y 
no con una función puramente coercitiva. Un especie de agente alentador del ser humano que garantiza evolución permanente. Entonces el Estado no es solamente una garantía contra las ofensas, un guardián o un Estado gendarme; sino que es un órgano de propulsión, de progreso y de coordinación de la actividad humana. Dicha característica del Estado correspondió en un momento determinado a la generación de un organismo comprometido con la sociedad, fuente de desarrollo social y personal, pero orientando sus objetivos no sólo a la unidad nacional. Esta imagen del Estado preocupado por el bienestar de los individuos también tiene prioridades, como aquellas personas con problemas físicos o mentales. Lo natural es que este Estado provea de las condiciones adecuadas a estos grupos para que cuenten con la protección debida ante tal situación personal, pero además concebir un sistema económico capaz de conquistar esos objetivos.

Por otro lado, este Estado debe proponer expresiones culturales que permitan potenciar el intelecto y reforzar áreas prioritarias para la sociedad (como la educación) para lograr la valoración de la memoria histórica y su traspaso generacional. Esto se traduce en un estado al servicio del hombre, de sus intereses y a la creación de ellos, complementando sus propias inquietudes con otros Estados extrafronteras y procurando no desviarse de su objetivos iniciales. Se puede sostener en esta misma línea que el Estado “(...) no es un actor racional, ajeno y separado de la sociedad, sino que forma parte de una configuración política más o menos fluida, compleja, inestable; esa configuración ha cambiado en los últimos tiempos" (Escalante, 2007: 64). Hay un constante movimiento en la utilidad del Estado, influenciado por cuestiones externas y moldeado por elementos surgidos desde la globalización o de nuevas problemáticas sudamericanas. Pero lo relevante de toda esta breve teorización sobre el Estado estriba en que sus funciones han ido variando con el paso del tiempo, conviviendo con la carestía de recursos económicos, planificando la generación de estrategias de desarrollo tendientes a subsanar las diferencias sociales en la región y experimentando un quiebre interno producto de la ofensiva neoliberal de los años setenta. Así se puede colegir que el Estado “(...) no sólo es la representación jurídica de la Nación o un conjunto de estructuras administrativas sino, sobre todo, su máxima representación política. Por eso, una de sus funciones más importantes y menos estudiadas consiste en garantizar un espacio vacío de poder estatal, una zona propiamente política, que es donde se resuelven las disputas y los conflictos entre los partidos que buscan acceder al Estado" (Mires, 2007: 141). Por otra parte, desde una dimensión económica, la fórmula del desempeño estatal imperante en gran parte de Latinoamérica 
entró en un escenario de agotamiento crónico, dando cabida a la crítica desde sectores tecnocráticos que percibían que el mercado era un modelo de eficiencia y de buena gestión. Es por dicha coyuntura económica que surgiría en América Latina ( $\mathrm{AL}$ ) un debate entre Estado y mercado, provocando una fuerte polarización argumentativa, aunque reconociendo que no pocos intelectuales son partidarios de éste último y resultando imperioso para ellos el dotar al Estado de una razonable "modernización" en su composición interna. Es así como ese Estado de los años treinta, que se consolida en respuesta a la pérdida de posición internacional de los países de la región, se transformó en la piedra angular de una clase media emergente y a la vez canalizó sus demandas para obtener un mayor crecimiento social. A partir de este momento, sus fórmulas de consolidación social se tradujeron en la Industrialización por Sustitución de Importaciones (ISI) y en una fuerte inversión en infraestructura. Pero además, el Estado “(...) expande los servicios públicos y promueve cambios estructurales (propiedad de recursos naturales, reforma agraria) con el fin de integrar a los sectores medio y popular" (Lechner, 1992: 237). Entonces se pueden identificar como las principales características del Estado el llamado modelo de desarrollo hacia adentro desde lo económico y desde una dimensión política el llamado Estado de compromiso; entendiendo esto como una situación en donde no hay más hegemonía absoluta de un sector social al interior del Estado -como lo fue en la época oligárquica- sino por acomodaciones inestables entre sectores incluidos: oligarquías, diversas fracciones de la burguesía, capas medias y trabajadores industriales. Por otro tipo de populismo, independiente de los regímenes políticos ${ }^{3}$. El resultado de esto fue una fusión entre Estado, partidos políticos y actores sociales y "en la mayoría de los casos, la forma privilegiada de la acción colectiva era la política, y la parte más débil de la matriz eran las relaciones institucionales entre sus componentes, es decir, el régimen político, independiente de su naturaleza (democrática o autoritaria)" (Garretón, 2000a: 30). Esta supremacía del Estado en la composición y articulación social se prolongó hasta los años setenta, época en que los regímenes autoritarios se instalan en el poder y descomponen el protagonismo del Estado, desencadenando la ruptura de la matriz clásica predominante en $\mathrm{AL}$, esa que se define como nacionalpopular. Sin embargo, ya en los años sesenta comenzaron a plantearse las primeras recomendaciones a las debilidades y defectos de la ISI.

\footnotetext{
${ }^{3}$ Para una mejor comprensión del término recomendamos el texto Política y sociedad entre dos épocas: América Latina en el cambio de siglo de Manuel Antonio Garretón.
} 
No obstante, todos los actores relevantes se acostumbraron a una modalidad cuyos rasgos característicos eran altos precios relativos para los bienes de producción local y una constante dependencia del capital extranjero y de la exportación de commodities para financiar las importaciones. Las consecuencias económicas a fines de la década de 1960 fueron inflación, excesivo endeudamiento externo, baja inversión, déficit en la balanza de pagos, estancamiento de la producción de alimentos y creciente desempleo. La proclamación del agotamiento de la ISI era habitual en la región desde la década de 1970 (Ibíd, 2004: 33).

El clásico modelo que había predominado en AL durante casi cuatro décadas entró en una fase de incumplimiento de sus responsabilidades adquiridas, y proyectando de esta forma que una fase de la historia económica regional había cumplido un ciclo. La crisis del Estado desarrollista comienza a manifestarse no sólo en la crítica a su rol, sino que, además, se redefine el modelo de desarrollo. Para el caso que convoca este trabajo, la dictadura militar chilena le asignó al mercado una fuerza socioeconómica mayor que el que había obtenido el Estado de compromiso, insistiendo por sobre todo en los beneficios y en las diferencias que tiene el mercado sobre el Estado. Fue así como "la instauración de la dictadura militar en 1973 constituyó un auténtico proceso de transformación del modelo de desarrollo chileno. Esto significó una profunda reforma estructural de la economía chilena, orientándola hacia una economía de mercado" (Alegre, 2007: 96). Desde ese momento el mercado se perfiló como la gran solución a los dilemas económico-sociales en Chile y el neoliberalismo como el sistema que lo consolidaría. La ISI sería terminada definitivamente por la dictadura, ya que se consideró como una estrategia artificial y forzada, y que debía ser reemplazada para fomentar otros sectores de la economía, como la minería, la pesca o la agricultura.

Es así como, teóricamente hablando, el mercado puede ser considerado como “(...) una institución más limitada, pero también fundamental: es el mecanismo de competencia económica regulado por el Estado que logra una coordinación relativamente automática entre las acciones económicas; es la institución que complementa la coordinación más amplia realizada por el Estado" (Bresser-Pereira, 2009: 84). Para este autor se produciría una especie de complementación entre el Estado y el mercado, pero no se podría producir una tensión entre ambos, ya que es perfectamente posible una coordinación entre ellos, aunque es el Estado el que tiene una responsabilidad mayor en algunas decisiones. Lo anterior quiere decir que "(...) el Estado siempre regulará los mercados. La responsabilidad final por la buena o mala coordinación no será del mercado, que no tiene voluntad, 
sino de la sociedad, que a través de sus formas de organización política -la sociedad civil o nación- constituye su Estado" (Ídem). Probablemente esta regulación estatal sea efectiva en algunos países pero el discurso que el sector tecnocrático elaboró y hegemonizó en Chile, se organizó bajo tres ideas fuerzas, una de las cuales apuntaba a la libertad económica. Aquí no es posible que el Estado intervenga en alguna toma de decisiones, minimizando su responsabilidad en su actuar y posibilitando que el individuo se desarrolle sin presiones de partidos políticos o de burocracia estatal alguna. "Entonces, la libertad económica es definida como el derecho a desplegar iniciativas económicas en el mercado sin ser coartado por el Estado, o, en otras palabras, como el derecho de cada individuo de tomar sus propias decisiones en materia de producción y consumo" (Vergara, 1984: 115). Por ende, sin libertad económica es imposible pensar en una libertad política y no se estimularía la igualdad social.

Otra de las interpretaciones del mercado fue dada por Geoffrey Hodgson, quien sostuvo que el mercado "(...) comprende un conjunto de instituciones, y en él tienen lugar numerosos cambios de bienes específicos de forma más o menos regular. Esos cambios son facilitados, e incluso estructurados por las instituciones, y comprenden tanto acuerdos contractuales como alteraciones en los derechos de propiedad" (Geoffrey en Gómez, 2005: 47). Hay una suerte de marco referencial bajo el cual opera el mercado, que le permite alcanzar un alto grado de intercambio económico y desplegar ciertos márgenes de autorregulación, como por ejemplo los precios. Esto significa que "la economía de mercado es una economía gobernada por los precios del mercado y únicamente por ellos (...) Los precios se establecen mediante las así llamadas leyes de la oferta y demanda. Las variaciones en la relación entre oferta y demanda harán, además, que esos precios no sean nunca estables sino que se hallen en permanente fluctuación" (Polanyi en Prieto, 1996: 25). Como los precios sufren constantes oscilaciones, los mercados buscan el espacio justo para que se les reúna y les apoyen en sus intercambios comerciales y en la búsqueda de la institucionalidad. Su resultado es que "la institucionalización de los mercados permite la resolución colectiva de un conjunto de problemas globales, en cuanto a los problemas encontrados en los mercados, la mayoría están relacionados con la acción humana, ya que no son problemas de optimización matemática" (Dugger, 1998: 287-303). Este alto compromiso institucional de los mercados le estipula un alto margen de tecnicidad en sus componentes internos, pero sus movimientos impactan en los individuos y en gran parte de sus actividades sociales. Si bien el individuo adquiere cierto reconocimiento al interior de ellos, éste reformula y trastoca el sentido gregario del individuo. Pasa del 
homo socialis al homo economicus, entendiendo esto como el predominio del ser individualista en desmedro de ese ser humano más sociable. El sujeto que nace es un ser autónomo, aislado y cuya satisfacción personal está determinada por el acceso a algunos bienes materiales. "Surge así un individuo egoísta que se mueve por las determinaciones internas del deseo, que debe vencer cualquier límite que se oponga a su consecución (...) Su único fin natural es la adquisición ilimitada o indeterminada de bienes por satisfacer un deseo ilimitado" (Lahera, 1999: 38). Es así como el mercado destruye las relaciones sociales que tradicionalmente eran comunitarias entre los individuos e instala en ellos nuevos vínculos de relaciones societales, y otros componentes fundamentales para la subsistencia del mercado, como la competencia entre los sujetos, la búsqueda incesante por el interés material y la acumulación de ganancias personales. "Por tanto, el utilitarismo del individualismo creado por el análisis económico establecía la competencia entre los seres humanos como el eje fundamental de organización de la sociedad, todo lo cual obedecía a un orden natural y, por tanto, irrebatible" (Idem). Es en el mercado donde el poder y las nuevas oportunidades particulares se comienzan a socializar, permitiendo que los vínculos comerciales derivados de las oportunidades brindadas por el mercado y sus relaciones directas, incidan en que el poder se traslade a las masas y no continúe en las burocracias estatales. "En consecuencia, es el mercado -y no el poder social o el pueblo organizado en sus bases- el que actúa como límite del poder estatal y garantía de la libertad individual" (Vergara, 1984: 116). La libertad económica es entonces un valor fundamental para el surgimiento de los sujetos, pero insistiendo en que el Estado debe reducir su poder coercitivo y traspasarle a los privados la capacidad de decidir por el bien social. Fue así como la tecnocracia nacional presentó dos formas de enfrentar los desafíos en Chile: por una parte un totalitarismo encarnado por el Estado y por otro lado, la libertad personal que estaba representada por el libre mercado. Había que decidir entre el crecimiento y el estancamiento, entre la pobreza y la riqueza, cuestiones que el Estado y el mercado reflejaban respectivamente a los ojos neoliberales. Por tanto, “(...) se sustantiviza el significado formal de lo económico en el que el 'hombre económico' era el hombre real y el sistema económico era realmente la sociedad" (Lahera, 1999: 39). Asimilando que el mercado se transformaría en el nuevo espacio de desenvolvimiento social, este escenario societal tendría como corolario la impersonalización de las relaciones entre los sujetos, la creación de igualdades de oportunidades y el término de las arbitrariedades cometidas por el Estado en épocas preliminares. Por ende, la organización de la sociedad estaría regida por el mercado, destacando los beneficios que los individuos 
podían obtener de el y enfatizando en la competencia como el único medio utilitarista para la obtención del prestigio social. En definitiva, el mercado altera profundamente las pautas de comportamiento, modifica sus fórmulas de vinculación personal e idealiza el desarrollo personal. El resultado es que se construye una sociedad altamente dividida, identificándose finalmente como una sociedad postindustrial (Bell, Touraine), en una sociedad postmoderna (Kumar), en una sociedad del riesgo (Beck), en sociedad de la información (Castells), en sociedad global (Albrow), en sociedad mundial (Luhmann), en una sociedad industrial de Estado nacional o la sociedad postindustrial globalizada (Garretón) o como se podría profundizar, en la sociedad de la incertidumbre. Cada reflexión acerca de la sociedad es atingente, pero para los objetivos de este trabajo, se utilizará la conceptualización de Garretón.

A juicio de ese autor existirían dos tipos societales que estuvieron presentes en la región y que incidieron notoriamente en las formas de relacionarse entre los individuos. Una de ellas se denomina sociedad industrial de Estado nacional (SIEN) y la segunda es la sociedad post-industrial globalizada (SPIG). Las principales características de la SIEN estaban definidas por un sistema económico, un modelo político, una forma de organización social y una dimensión cultural en correspondencia con un territorio determinado. Acá, economía y política consiguen una importancia superlativa, ya que sobre ellas se van articulando las clases sociales y sus distintos referentes. Por ejemplo, la clase obrera, la clase media y la burguesía, como también los partidos políticos y ciertas organizaciones que giren en torno a los partidos. Todos estos componentes definen a la sociedad, la cual posee límites y los que se asocian con la polis. "La sociedad industrial de Estado nacional se constituyó como sociedad polis, lo que significa que tiene un 'centro' de toma de decisiones, que puede ser democrático, autoritario, monárquico, o de cualquier otro tipo. La política, en cualquiera de sus formas es la expresión principal de la vida social y ello fue especialmente cierto en sociedades construidas desde el Estado" (Garretón, 2000: 32-33). Este punto es central en el cuadro político latinoamericano de los años treinta, por cuanto el ejercicio político era una forma de desenvolvimiento personal, el medio para expresar algunas reivindicaciones comunitarias o simplemente la cualidad con que la sociedad se relacionaba con el Estado. Un punto clave de este cuadro político fue el concepto de desarrollo, que le impregnaba continuidad o cambio a la sociedad a partir de esta estrategia social. Este desarrollo sostenido hacia adentro presentaba rasgos característicos para su concreción, como el crecimiento de la producción, una expansión de los beneficios generados por la gestión estatal, el crecimiento económico 
y algunos elementos éticos asociados preferentemente a la igualdad en la distribución de esos recursos. Surge entonces el concepto de Matriz SocioPolítica (MSP), que para estos años asume una identidad nacional-popular, definiendo a la MSP como la manera de entender las “(...) relaciones entre el Estado, una estructura de representación o un sistema de partidos políticos (para agrupar demandas globales e implicar políticamente a sujetos) y una base socioeconómica de actores sociales con orientaciones y relaciones culturales (lo que incluye la participación y diversidad de la sociedad civil fuera de estructuras estatales formales), todo ello mediado institucionalmente por el régimen político" (Ibíd, 2004: 16-17). La MSP nacional-popular es entonces la manera de cómo se entiende la realidad política latinoamericana, pero incluyendo factores culturales, económicos, sociales, y la combinación de cada uno de ellos.

La segunda manera de concebir a la sociedad se le conoce como Sociedad post-industrial globalizada (SPIG), pero que a diferencia de la anterior, se desplegó gracias a los fenómenos de la globalización, la desarticulación del Estado, los regímenes militares, la desaparición de la industria como espacio de desarrollo nacional, la satanización de la política y la transformación de la economía local. Entonces “(...) puede afirmarse que la organización de este tipo societal se hace en torno al consumo y la comunicación, es decir, lo social y lo cultural, a diferencia de la sociedad industrial nacional que se organizaba en torno a la economía y la política" (Ibíd, 2000: 36). Hay dimensiones de la SPIG que se atenúan y otras que se fortalecen, pero todo esto se produce por la cristalización de otros ejes fundamentales que dominan a este tipo societal. "No es que no haya trabajo, no es que no haya producción (...) Esquematizando, el lugar de encuentro de la gente no es la fábrica ni el partido ni la asamblea, son los 'mall' y el espacio público creado por los medios de comunicación de masas. Tampoco desaparecen los partidos y la política, pero se agregan nuevas modalidades de espacio y acción públicas que modifican las anteriores" (Ibíd, 37-38). El resultado de toda esta nueva configuración social conduce a una desnormativización de la sociedad, careciendo ésta de la creación de instituciones que la representen, y redundando en que el propio Estado sea desplazado de su sitial de organismo referencial.

Por otro lado, los mecanismos de confrontación o desarrollo social sufren un giro importante, puesto que si bien durante la presencia de la SIEN el principio de avance social apuntaba al modelo de desarrollo, en la SPIG esto fue reemplazado por los avances tecnológicos; si las formas de exclusión social durante el predominio de la SIEN fueron dadas por la explotación del individuo, bajo la SPIG la exclusión está determinada por ingresos, 
poder o nivel educacional. Si antes las utopías se relacionaban con el socialismo o el comunismo, durante la SPIG emergen nuevos componentes de representación social, como los temas de género, medioambiente o de identidad. Por ende, las diferencias entre cada sociedad es notoria, pero hay un elemento clave en el quiebre que sufrió la SIEN: los regímenes autoritarios. Dichos regímenes influyeron en el desplazamiento de la SIEN hacia la SPIG en la vida social de Latinoamérica y permitieron el tránsito desde una matriz nacional-popular a otra matriz, cuyos componentes esenciales son definidos por el mercado. El resultado fue que "buena parte de los países de la región giraron desde modelos industrializadores, estado-céntricos y orientados al mercado interno, hacia modelos exportadores, mercado-céntricos e integrados a los mercados internacionales" (Alegre, 2007: 90). Se logró por una parte que la forma de percibir el Estado sufriera una mutación y a la vez fuera objeto de serios cuestionamientos a su desempeño. Como segunda cuestión, el mercado fue considerado como el único sistema que garantizaría nuevas oportunidades a los individuos y el que produciría el repliegue final del aparato estatal.

\section{EL PROYECTO AUTORITARIO Y LA RUPTURA DEL ESTADO DE COMPROMISO}

La interrupción de la democracia chilena el 11 de septiembre de 1973 a manos de los militares, no solo significó el quiebre de la vida republicana que se desarrolló intensamente en el país por más de un siglo, sino que, además, alteró la estructura social interna y delineó los objetivos fundamentales que guiaron a la dictadura. Entre los propósitos centrales que se pueden descifrar están el generar un proceso refundacional y de restauración societal, reconstruir a Chile sobre nuevas bases políticas, solventar las medidas estatales bajo una nueva propuesta económica y, finalmente, invisibilizar todo legado institucional del gobierno anterior. Por otro lado, la alteración de la institucionalidad chilena implicó la creación y utilización de algunos mecanismos de represión gubernamental, el cese de toda actividad legislativa y el reemplazo de ésta por una junta de gobierno, la proscripción de los partidos políticos, la limitación de las libertades individuales, el término de las elecciones democráticas, el control del aparato judicial y la elaboración de una nueva Constitución. Sin embargo, uno de los grandes objetivos del sistema autoritario fue debilitar el tradicional rol del Estado y aminorar la excesiva injerencia socioeconómica alcanzada por éste durante el gobierno de Salvador Allende. Por ejemplo, Baraona y De Castro coincidieron en 


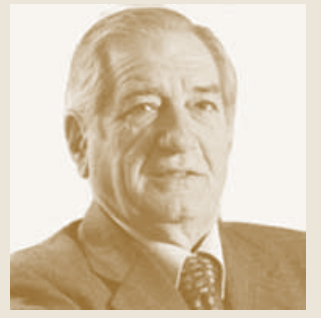

P. Baraona que “(...) la inorganicidad que durante esos tres años había adquirido la expansión del aparato público y la multiplicidad de las trabas y controles al libre funcionamiento de los mercados" (Vergara, 1984: 24) fueron las auténticas consecuencias de los desequilibrios económicos de esos momentos y los cardinales elementos que frenaron la participación de los particulares en el fortalecimiento de la economía. El aparato productivo cayó irremediablemente en una ineficiencia gubernamental que era necesaria reformar, pero cuyo resultado significó una sobrevaloración del mercado por sobre el Estado.

Por otro lado, las tradicionales fórmulas de expansión e intermediación social aplicadas por el Estado, así como la representación social y la acción colectiva, fueron eliminadas en su totalidad y ágilmente suprimidas. La dictadura militar acabó con la acción política de los grupos sociales de los años setenta, ya que el éxito de su -aparente- proyecto "modernizador", implicaba el total control social, el término de las actividades partidarias y el refuerzo de los mecanismos de represión doméstico. La participación de grupos tecnocráticos en la conformación de este "modelo" autoritario en lo político y neoliberal en lo económico, fue coronada con la instalación de los Chicago Boys en la dirección económica castrense y amparada bajo el paraguas estatal. La intervención en la economía a manos de esta tecnocracia, posibilitó el aterrizaje de los grupos económicos emergentes, quienes consolidaron y apoyaron la alteración y recomposición del Estado, el que se consideraba había aumentado demasiado en su estructura interna y acelerado la delicada situación económica. "Frente a esta realidad, la gestión económica debía centrar sus esfuerzos en la aplicación de una política económica de emergencia que pusiera término al caos heredado y reestableciera los principales equilibrios macroeconómicos. Sólo así sería posible "crear las condiciones para que (volviera) a imperar una normalidad relativa en el acontecer económico" (Ibíd: 25). Los desajustes de la economía chilena bajo la UP prontamente serían encauzados por la tecnocracia local, impulsando el proceso de privatización nacional, la liberalización gradual de los precios que estaban controlados por el aparato estatal, la fijación de los salarios, la liberalización del mercado financiero, la devolución de algunas empresas y tierras a sus antiguos dueños y lo más significativo, la desaparición de los derechos sindicales de los trabajadores del país. El propósito que tuvieron estas reformas era no sólo restarle injerencia a los actores sociales y al mundo sindical, sino que por lo demás, mitigar el activo funcionamiento del Estado como promotor de la inversión y de la industrialización. "El papel tradicional del Estado como empresario (...) debía reducirse en el más breve plazo posible para que estos procesos resultaran exclusivamente 
de las decisiones tomadas por los agentes privados en mercados liberalizados y abiertos al exterior" (Ffrench Davis, 2001: 27). Se provocó entonces el desmantelamiento del Estado en toda su dimensión subsidiaria, se procedió a promover una reforma tributaria, un recorte en el gasto público y la desregulación de los plazos de los créditos financieros con el sentido de elevar los niveles de crecimiento económico. Sin embargo, las medidas aplicadas para "normalizar" y "sanear" la economía pronto acarrearían costos sociales y particularmente las carteras de salud, educación, seguridad social y vivienda sufrirían las principales consecuencias. De esta manera “(...) se produjo una abrupta disminución del gasto fiscal: de 29,1\% del PNB en 1972, a un 19,7\% en 1978; la inversión fiscal cayó casi a la mitad entre 1970 y 1978. En un solo año el gasto por habitante se redujo en educación en un $21 \%$, en salud en un $23 \%$, y en vivienda en un $43 \%$; la pensión mínima se vio disminuida en un tercio. Las tasas de desempleo, si en los primeros años alcanzaron a ser tres veces superiores a la media histórica, luego se volvieron crónicas, hasta llegar al 30\% entre 1982 y 1983" (Correa, Figueroa, Jocelyn-Holt, Rolle, Vicuña, 2001: 293). En esa línea reduccionista, el sector público asistió a un empeoramiento de sus condiciones laborales impuestas por la dictadura, situación derivada del alto grado de ineficiencia conseguido en materia económico-social. Se intentó (y se consiguió) satanizar al Estado en sus formas de operar, considerándole el único responsable del deterioro económico por el que atravesaba el país, insistiendo en que sus acciones fueron confeccionadas bajo criterios políticos por sobre los criterios técnicos, con el único objetivo de controlar a la sociedad en su totalidad y asegurar a ciertos sectores marxistas el control político-económico del país. Frente a esa cartografía socioeconómica, el pinochetismo fue asignando un valor agregado al mercado en términos de eficacia y eficiencia, planteando, a su vez, que el mundo empresarial encarnaba los valores de la "modernización chilena" necesarios para revertir el mal manejo económico anterior. Como secuela, el proceso de privatización que perturbó al sector público destruyó en gran medida las aspiraciones de sus empleados y dio como resultado un masivo éxodo de funcionarios fiscales "castigados" por su responsabilidad en la crisis interna de la primera mitad de los setenta. "Así, se promovió una noción extremadamente negativa del rol del Estado (...). El pensamiento político dominante asoció al sector público con anticuadas, burocráticas y anacrónicas ideas e imágenes. Como consecuencia, todos los empleados públicos fueron injustamente considerados como ineficientes" (Garretón, 2009: 57). Es por ello que el proceso de reforma del Estado se transformó en algo inevitable para responder a las verdaderas exigencias de la ciudadanía, transitando así desde el tradicional modelo de 


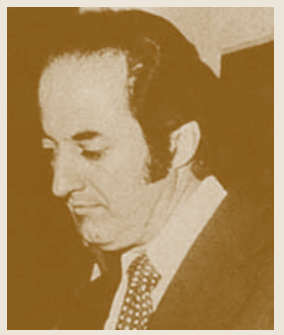

S. de Castro

desarrollo "hacia adentro" impulsado por el Estado, hacia un modelo de desarrollo "hacia fuera" mediatizado por actores privados ultraortodoxos y ultradefensores del mercado. Los esfuerzos iniciales se focalizaron fundamentalmente en disminuir la vertiginosa inflación heredada del gobierno anterior y fomentar la depreciada inversión interna, aunque la primera se convirtió en prioridad. Si bien la inflación estaba desatada bajo la UP (se especulaba de $1.000 \%$ ), sus orígenes no podían atribuirlas única y exclusivamente a errores por parte del Estado, ya que sus desbordes tienen explicaciones más de fondo y, por lo general, presentes al interior de los sistemas económicos. Este problema fue la principal excusa tecnocrática para impulsar medidas que cambiaran la posición predominante del aparato estatal, sosteniendo que los errores del gobierno anterior y el avanzado intervencionismo gubernamental asfixiaron y condicionaron la iniciativa económica particular. Sergio de Castro en 1978 expuso sobre el Estado de la Hacienda Pública lo siguiente: "La gestión administrativa del país por parte del Gobierno anterior de la Unidad Popular condujo a una profunda crisis social y económica. En el aspecto puramente económico, un análisis detenido de estos tres años de gobierno lleva a la conclusión de que no hubo cambios de orientación de la política económica (...) Ello hizo aflorar en toda su magnitud una crisis que se venía gestando a lo largo de medio siglo" (De Castro en Vergara, 1984: 96). La inflación de los años setenta se percibió como una molestia que había que erradicar a la brevedad, pero dicha salida no podía encauzarse desde el Estado, debido a que dicha entidad era la responsable de los errores económicos. Los opositores al protagonismo del Estado instalaron en el debate la noción de que sólo una economía de libre mercado sería competente para garantizar el pleno equilibrio entre la oferta y la demanda y una mejora en la entrega de los recursos. "Se trata de provocar una ruptura radical y drástica con el esquema de funcionamiento de la economía vigente en el país por más de 30 años, para encaminarse hacia una economía de libre mercado y apertura externa, lo que implica el repliegue definitivo del Estado del ámbito económico, la plena integración de la economía al comercio internacional, el libre flujo de capitales externos y la total liberalización del mercado de capitales" (Ibíd: 98). De este modo, se produjo una fuerte relación entre el mundo privado local y los grupos económicos internacionales que conducirían la economía chilena para reconstruirla y reemplazar la figura del Estado de compromiso por el predominio del mercado. Progresivamente el Estado de compromiso fue desplazado del centro de la importancia socioeconómica y junto a ello, la matriz sociopolítica denominada para este trabajo nacional-popular asistió a su progresivo repliegue. "Los regímenes militares de nuevo tipo que comenza- 
ron durante los años setenta y el proceso de globalización con sus consecuencias económicas, desencadenaron la crisis de esta matriz y su descomposición o desarticulación" (Garretón, 2000a: 30). Este proceso de desarticulación de la matriz significó que la sociedad chilena experimentara la generación de una nueva matriz sociopolítica, cuyo centro referencial es el mercado, acompañado de otros componentes que le sustentan. Por ejemplo el sistema financiero, la globalización, un modelo de crecimiento por sobre el desarrollo, y el protagonismo de actores privados por sobre la función del Estado. Es por ello que "el intento de desmantelar la matriz clásica o político-céntrica por parte de los regímenes militares de los setenta y algunas trasformaciones institucionales o estructurales que también ocurrieron en otros países sin este tipo de autoritarismo, en los ochenta, implicaron algunas consecuencias profundas para los actores sociales y formas de acción colectiva" (Garretón, 2001: 17). Sociedad, Estado y política advierten una suerte de desarticulación entre estas unidades, puesto que el mercado logró ubicarse en una dimensión superior y desde ahí forzar un notorio debilitamiento a la gestión del Estado. Por ello, "los nuevos elementos ingresados al mercado debían contar con dueños y expresar un valor económico. La idea de capital social o capital humano se volvió un concepto común, y si bien existen versiones de este concepto que tienen elementos positivos, no se puede dejar de advertir el hecho, no menor, de haber escogido el término capital para definir estos nuevos enfoques" (Gudynas, 2009: 56). El resultado de todo esto fue que las medidas aplicadas por la dictadura tuvieron tal profundidad en el Chile de los setenta, que el proceso de democratización de lo noventa difícilmente pudo revertir. Esa confianza en el Estado desde comienzo de los años treinta hasta los años setenta se fue reduciendo como resultado de las malas cifras económicas y de las escasas posibilidades de darle una sana solución ${ }^{4}$. Probablemente estas evaluaciones podrían ser objeto de cuestionamiento empírico, sin embargo, la opinión de los entrevistados con respecto al fenómeno de las privatizaciones en Latinoamérica es contradictoria. Para el año 1998 un alto porcentaje de la población consideró que el fenómeno de las privatizaciones había sido beneficioso (45\%), pero con el paso de los años, con crisis económicas, altas

\footnotetext{
${ }^{4}$ Por ejemplo esta tendencia a una mirada optimista de resolución de problemas por parte del Estado se tradujo que para el año 2003 cerca de un 57\% de los latinoamericanos consideraban que el Estado era una institución poderosa. Sin embargo, ya para el año 2005 esa cifra se redujo a un $49 \%$. En contraste con lo anterior, los consultados le asignaron un $40 \%$ de poder a las grandes empresas para el año 2003 y en 2005 esa cifra llegaría al 44\%. Corporación Latinobarómetro (2005: 18).
} 
cifras de desempleo y una no menor cuota de incertidumbre, esta realidad se alteró. Ya para el año 2005 dicho dato bajó a un 31\% y en 2008 marcaba un $32 \%$. En definitiva, la valoración de los latinoamericanos para con el Estado es mayoritaria y fundamental para resolver los problemas de la ciudadanía. Esta situación ha permitido que "(...) desde hace ya algunos años ha comenzado a recuperarse la idea de la centralidad del Estado para el desarrollo y la democracia. Junto con ello, se ha comenzado a revalorizar su papel redistribuidor y la idea de la inversión social como clave para la reducción de las desigualdades" (Cunill, 2009: 35). Quizás la ciudadanía espere el regreso de un Estado como lo fue en los años treinta, aunque habría que evaluar si el Estado está en condiciones de enfrentar algunos desafíos propios de una sociedad posindustrial globalizada.

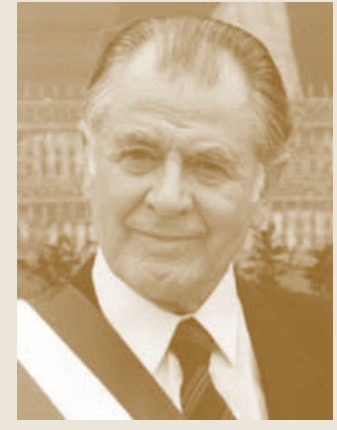

P. Aylwin

\section{TRANSICIÓN DEMOCRÁTICA Y MATRIZ MERCADO-CÉNTRICA EN LOS NOVENTA: CUANDO EL MERCADO INVISIBILIZÓ AL ESTADO}

La transición a la democracia ocurrida en Chile a principios de los años noventa significó el cierre definitivo a todo recurso golpista con fines "reformistas" y la instalación de Patricio Aylwin (1990-1994) como el primer Presidente de Chile durante la apertura democrática. Entre sus metas dispuestas para sus cuatro años de gestión presidencial se destaca el desarrollar una política económica externa abierta y moderna que vinculara a Chile con los núcleos más representativos del crecimiento económico y de la innovación tecnológica, luchar por la defensa y el respeto de los derechos humanos, lograr un crecimiento con equidad y corregir los errores del modelo económico en materia social. El primero de los objetivos fue una pieza clave en la inserción internacional de Chile, pero con una profunda onda continuista de lo que fue el legado pinochetista y su espejismo económico. El primer gobierno de la Concertación no tuvo mayores sobresaltos y pudo implementar medidas sociales que revirtieran los bajos índices sociales que durante la dictadura militar se experimentaron. "Por ejemplo, el crecimiento económico en 1991 alcanzó un 7,3\% y en 1992 un 11\%. De 1990 hasta la recesión de 1998 producida por la crisis Asiática Chile mantuvo un crecimiento económico de 6,6\%. La inflación se redujo del 27,3\% en 1990 al 6,2\% en 1997 (...) El crecimiento sostenido también redujo el desempleo que alcanzó un 5,3\% en 1998, aunque subió a niveles superiores durante 1999, 11,5\% entre julio y agosto...” (Frank, 2000: 74). Si bien estos datos 
reafirman que el proceso de apertura democrática chilena tuvo un respaldo desde el manejo económico, hubo temas pendientes en los noventa que instalaron una nebulosa en la coalición de gobierno. Por una parte la sociedad no advirtió una plena democracia y el régimen político mantuvo ciertos enclaves autoritarios, pero lo más significativo fue que la promesa de crecimiento con equidad no tuvo los resultados esperados. "Lo más relevante es que ninguno de los gobiernos de Aylwin o de Frei han sido capaces o han estado dispuestos a avanzar verdaderamente en sus promesas de 'crecimiento con equidad' (...) Así es por ejemplo que sólo en 1995, a cinco años de la nueva democracia, los salarios reales recién comenzaron a aumentar y a aproximarse a los niveles de los inicios de los años ochenta" (Ibid: 75). Es más, si en 1978 el 20\% más rico de Chile controlaba el 52\% del ingreso nacional, dicha cifra aumentó a cerca del 60\% para 1996. Con relación al 20\% más pobre, este grupo para 1987 recibía sólo un 4,3\% del ingreso nacional y para 1990 esa cifra sólo llegaba al 4,4\%. Sin embargo, en 1996 esa cifra llegó al 4,1\% evidenciando un notable retroceso en las medidas para erradicar la concentración económica que durante la dictadura ya se estaba concretando. Uno de los mecanismos que habría posibilitado revertir aquella tendencia es haber impulsado un mayor margen de sindicalización, pero lamentablemente esta posibilidad de los trabajadores chilenos no fue reforzada y más aún, el proceso de sindicalización en Chile presentó retrocesos. Al margen de la reforma laboral que entró en ejecución en 1991 y comparándola con el Plan Laboral de José Piñera (1979) “(...) ésta se encuentra lejos de crear una situación que podría justificar el argumento en que empleadores y trabajadores estén negociando en un contexto de igualdad..." (Ibíd: 76). El mercado laboral definitivamente fue desequilibrado en esta materia, dando amplios poderes aun a los empleadores y dejando en muy mala opción de negociación a los empleados 5 .

Un segundo tema clave en esta evaluación al Estado, el mercado y la sociedad de los noventa, apunta a los enclaves autoritarios que coartan la posibilidad de aplicar medidas tendientes a favorecer a la población en situaciones de crisis económicas por ejemplo. De todas formas el gran enclave lo representa la Constitución de 1980, que por dos razones la transforman en la gran herencia pinochetista. Uno, la Constitución es fruto de una co-

\footnotetext{
${ }^{5}$ Si se compara la capacidad de negociación colectiva que tienen algunos sindicatos en Chile con Europa, los datos nos sitúan muy por debajo de lo que se estila en países desarrollados. En algunos países que conforman la UE, el margen de negociación colectiva alcanza el 90\%, pero para el caso chileno esa cifra es paupérrima y llega al 8,6\%.
}

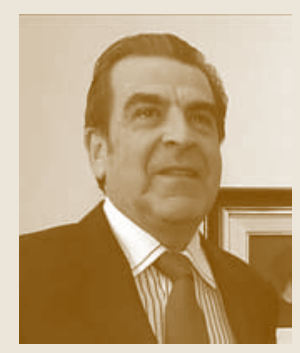

E. Frei R.-T.

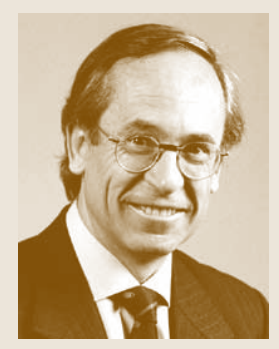

J. Piñera 


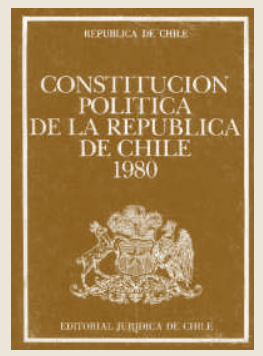

misión de estudio que en ningún caso representó pluralidad alguna en su creación y como segundo tema, la aprobación de la nueva Carta Magna se produjo bajo un plebiscito carente de cualquier garantía democrática. "Todas estas circunstancias que afectan a la Carta Magna no han permitido lograr, a casi veinte años de su entrada en vigor, el necesario consenso y aceptación por parte de los miembros de la sociedad política, constituyendo más un elemento de controversia que de unión entre los chilenos" (Cazor, 2000: 27). Ésta fortalece a los poderes fácticos, se excluye a la sociedad en temas relevantes para su cohesión y además, se evita entrar en una tensión permanente, en un debate fecundo y en un conflicto necesario. Se puede argüir que la democratización política en Chile fue exitosa, ya que intentó desplazar a la dictadura de su sitial predominante, “(...) Pero no puede hablarse de 'transición ejemplar' o 'exitosa' si se consideran el resultado de este proceso y la calidad de este régimen democrático. Este se caracteriza por la precariedad institucional, la presencia de poderes fácticos y la debilidad de representación..." (Garretón, 2009: 61). Los gobiernos de Patricio Aylwin y de Eduardo Frei se limitaron principalmente a consolidar el "modelo económico" heredado de la dictadura por sobre la consolidación de algunos movimientos sociales proclives a reformas más de fondo y dañó irremediablemente la relación entre la sociedad, la política y los partidos políticos. El poder económico fue mucho más importante para esos años, sin negar los logros y los avances que en esa materia se adquirieron, pero que sin duda dejan a un Estado con menor grado de injerencia que el mercado y a una sociedad limitada sólo a aceptar y no a participar en debates claves para el desarrollo del Chile del siglo XXI.

\section{CONSIDERACIONES FINALES}

Una de las cosas incuestionables a la hora de hacer una evaluación al desempeño económico en los noventa por parte de los gobiernos de la Concertación, es que las cifras de superación de la pobreza, crecimiento económico o desarrollo humano dieron un pequeño salto cuantitativo. Sin embargo, hay temas que aún persisten desde la dictadura, como la concentración económica, la desigualdad social y las ganas de transformar al país en una nación desarrollada. Ya en algún momento José Piñera sostuvo durante la segunda mitad de los noventa que Chile, al llegar al Bicentenario, sería un país desarrollado. Según su opinión, los ajustes económicos aplicados bajo la dictadura conducirían a la concreción de ese anhelo, aunque la realidad 
fue diametralmente opuesta. La correlación entre crecimiento económico y progreso social no ha estado en simetría y los buenos resultados macroeconómicos sólo han beneficiado a un reducido sector que controla los medios productivos. Por ejemplo, los altos índices de desempleo y la poca capacidad de generación de puestos de trabajo ha gatillado que el mentado "modelo económico" chileno sea sólo un espejismo construido por los poderes fácticos y exacerbado por los medios de comunicación. Dicha situación podría ser remediada por la intervención del Estado, pero como la actual Constitución lo prohíbe, el desempleo será una cuestión crónica y muy difícil de reducir drásticamente. Además, la crítica que en el último tiempo se viene sosteniendo, apunta a que como el "modelo" se ha sustentado en las exportaciones, éstas han carecido de valor agregado y lo que es peor, no se ha producido ni la tecnología ni la innovación para alterar dicho fenómeno. El Estado ya no controla las decisiones políticas ni la agenda económica; ahora la política económica la controlan los agentes privados y se difunden en foros o en encuentros empresariales. Este grupo, más que proponer un modelo que signifique desarrollo colectivo, tiende a generar propuestas que fortalecen la acumulación. Por otra parte, la dictadura militar procuró que su drástica intervención en la sociedad debilitara los espacios de discusión política, se rompiera ese tradicional vínculo logrado entre Estado y sociedad y se forzara a que la militancia política se diluyera rápidamente. La despolitización de la sociedad, el debilitamiento del Estado como centro canalizador de las demandas ciudadanas y la extensión del mercado como fórmula de superación social, provocaron que la tradicional sociedad industrial de Estado nacional (SIEN) comenzara a decaer producto de los regímenes dictatoriales, sumado al sostenido proceso de privatización que sufrieron las empresas y los efectos directos de la globalización. La globalización -entendida ésta como un fenómeno de penetración o interpenetración de mercados, especialmente de tipo financiero por un lado y de comunicación e información, por otro- tiene alguna responsabilidad en el paso de una sociedad dominada por el Estado a otra donde los agentes privados, internet y organizaciones extrapartidos tienen una valoración incluso superior que la que obtuvo el Estado en épocas precedentes.

Otro de los temas que tiene elación con lo explicado en líneas anteriores se refiere a la descomposición de la matriz nacional-popular (MNP) y el rol que tuvo el Estado como agente movilizador y conductor de las medidas dirigidas hacia una sociedad más integral. Naturalmente que la matriz nacional-popular sufrió los embates de la dictadura, pues transformó sus ejes internos, descompuso la manera de articularse socialmente y difuminó 
sus formas de acción colectiva. Sin embargo, tradicionalmente esta matriz tuvo como condición suprema la superposición de ciertas fuerzas sociales y de los partidos políticos (centro o izquierda), que inclinaban las decisiones para mejorar el modelo de desarrollo. Pero el régimen militar con la creación de un nuevo sistema económico, no sólo buscó descomponer la MNP, sino que también transformar a la sociedad en su estructura interna e inyectarle valores muy cercanos al mercado: el individualismo, la competencia, la despersonalización y el consumismo. El mercado cumpliría fielmente con esos objetivos, siendo el sentido final de la dictadura, terminar con el predomio de la matriz y buscar una matriz alternativa. Probablemente se asista a una matriz mixta, de ruptura y continuidad, con elementos que provienen de la matriz clásica y se sumen a la matriz mercado-céntrica. Aún así, el Estado ha perdido supremacía a manos del mercado, la economía es mucho más independiente de la política, pero dependiente de los mercados internacionales. Entonces los desafíos que hay que enfrentar radicarían en hacer de la clásica matriz nacional-popular un estilo distinto al que se conoce en la actualidad y replantearla como alternativa a la matriz mercado-céntrica. Lo anterior permitiría que el país alcance altos niveles de desarrollo y de paso, que Chile retome la senda de la justicia social que alguna vez estimuló.

\section{REFERENCIAS}

Angell, Alan (1993). Chile de Alessandri a Pinochet: en busca de la utopía. Santiago: Andrés Bello.

Alegre, Pablo (2007). "Matrices sociopolíticas y patrones de reforma en el Cono Sur: entre la ruta populista y autoritaria. El caso uruguayo en perspectiva comparada”. Revista de Ciencia Política 2, vol. 27.

Bresser-Pereira, Luiz Carlos (2009). "Assalto ao Estado e ao Mercado, Neoliberalismo e teoria Econômica". Nueva Sociedad 221.

Cazor Aliste, Kamel (2000). "Democracia y Constitución en Chile". Revista de Derecho de la Universidad Austral Vol. XI.

Correa, Sofía; Figueroa, Consuelo; Jocelyn-Holt, Alfredo; Rolle, Claudio; Vicuña, Manuel (2001). Historia del siglo XX chileno. Santiago: Sudamericana.

Corporación Latinobarómetro (2005). Informe Latinobarómetro 2005: diez años de opinión pública 1995-2005, 176.554 entrevistas, 10 mediciones en 18 países. Santiago de Chile: Latinobarómetro.

Cunill Grau, Nuria (2009). "El mercado en el Estado". Nueva Sociedad 221.

Dugger, W. M. (1998). "Against Inequality". Journal of Economic Issues Vol. XXXII, 2, junio. 
Escalante, Fernando (2007). "Baile de máscaras: Conjeturas sobre el Estado en América Latina”. Nueva Sociedad 210.

Ffrench Davis, Ricardo (2001). Entre el neoliberalismo y el crecimiento con equidad: tres décadas de política económica en Chile. Santiago: Dolmen Ediciones.

Frank, Volver (2000). "El movimiento sindical en la nueva democracia chilena. Perspectivas de los dirigentes sindicales de base: ¿hechos o ficción?”. Revista Universum 15.

Garretón, Manuel (2000a). Política y sociedad entre dos épocas: América Latina en el cambio de siglo. Argentina: Homo Sapiens Ediciones.

------ (2000b). La sociedad en que vivi(re)mos: Introducción sociológica al cambio de siglo. Santiago: Lom.

------ (2001). “Cambios sociales, actores y acción colectiva en América Latina”. CEPAL 56.

------ (2004). América Latina en el siglo XXI: Hacia una nueva matriz sociopolítica. Santiago: Lom.

------ (2007). Del post-pinochetismo a la sociedad democrática: globalización y politica en el Bicentenario. Santiago: Debate.

---- (2009). “Transformación de la matriz sociopolítica y desarrollo en Chile”. Diplomacia, Estrategia y Política 9.

Gómez Uranga, Miguel (2005). "Fundamentos éticos del mercado en la teoría económica institucional”. Revista Ética y Economía 823.

Gudynas, Eduardo (2009). "Estado y mercado en América Latina: Una pareja despareja”. Nueva Sociedad 221.

Lahera, Arturo (1999). “La crítica de la economía de mercado en Kart Polanyi: el análisis institucional como pensamiento para la acción”. Reis 86.

Lechner, Norbert (1992). "El debate sobre Estado y mercado". Estudios Públicos 47. Disponible en: www.cepchile.cl [Consulta: 23.07.08].

Mires, Fernando (2007). "Estado y política: La lucha por la democracia en América Latina”. Nueva Sociedad 210.

O’Donnell, Guillermo (1997). Contrapuntos. Ensayos escogidos sobre autoritarismo y democratización (capítulo 2). Argentina: Paidós.

Prieto, Carlos (1996). "Kart Polanyi: Crítica del mercado, crítica de economía”. Política y Sociedad 21.

Vergara, Pilar (1984). "Auge y caída del neoliberalismo en Chile: Un estudio sobre la evolución ideológica del régimen militar”. FLACSO-Chile 216.

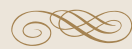

